\title{
Emerging Impacts of Smartphone: An Exploratory Study
}

\author{
Chiang-nan Chao, $\mathrm{PhD}$ \\ St. John's University (USA) \\ Email: CHAOC [AT] stjohns.edu
}

\begin{abstract}
Smartphones has provided their users many niches, particularly for mobile commerce, known as mcommerce. As smartphone penetration around the globe, it has rapidly altered the phone users and the market places, as US mobile devices have penetrated more than $80 \%$ of the population in 2017. The average adult daily usage of mobile devices outpaced personal computers for the first time, and the users have conducted more commerce activities on their mobile devices than on their personal computers. As a result, predicted by eMarketer, US mcommerce will be a half of the total ecommerce by 2022. The marketers realize that they can better find their customers on the move, and enable them to better target these customers for their products. This research, through an empirical survey, focuses on the smartphone user behavior. The research results provide some useful insights for marketers in their future marketing endeavors.
\end{abstract}

Keywords---- mobile commerce, mcommerce, electronic commerce, ecommerce

\section{INTRODUCTION}

US retail mcommerce sales increased about $23 \%$ in 2017 to $\$ 151$ billion. That translates to $35 \%$ of retail ecommerce sales and $3 \%$ of total retail sales for the year. The bulk of US retail mcommerce growth is in line with rapid growth of smartphone sales, as US smart phone has penetrated nearly $80 \%$ of the population in 2017 , and the average adult daily usage of smart phone had outpaced the uses of personal computers for the first time a year earlier (eMarketer, 2017; Statista, 2017).

Fourth-generation (4G) traffic exceeded third-generation (3G) traffic for the first time in 2015. In 2017, the 4G connection penetrated $87 \%$ of the US population (Wikipedia, online), while the mobile traffic accounted for about $9 \%$ of the total traffic. Mobile offload has exceeded cellular traffic for the first time since 2015. Fifty-one percent of total mobile data traffic was offloaded onto the fixed network through Wi-Fi or femtocell in 2015. In total, 3.9 exabytes of mobile data traffic were offloaded onto the fixed network each month (Cisco, 2017).

The phenomenon of rapid growing smartphones and mobile traffic become interest for the researchers to explore the smartphone user behavior, and this empirical study intends to focus on the smartphone user pattern, in order to learn some insights for marketer in their strategic thinking.

\section{REVIEW OF LITERATURE}

The global market for smartphones has increased rapidly in the past years that make it easier for the users to browse on the web for a variety of products. Figure 1 presents the global smartphone shipment in the past years.

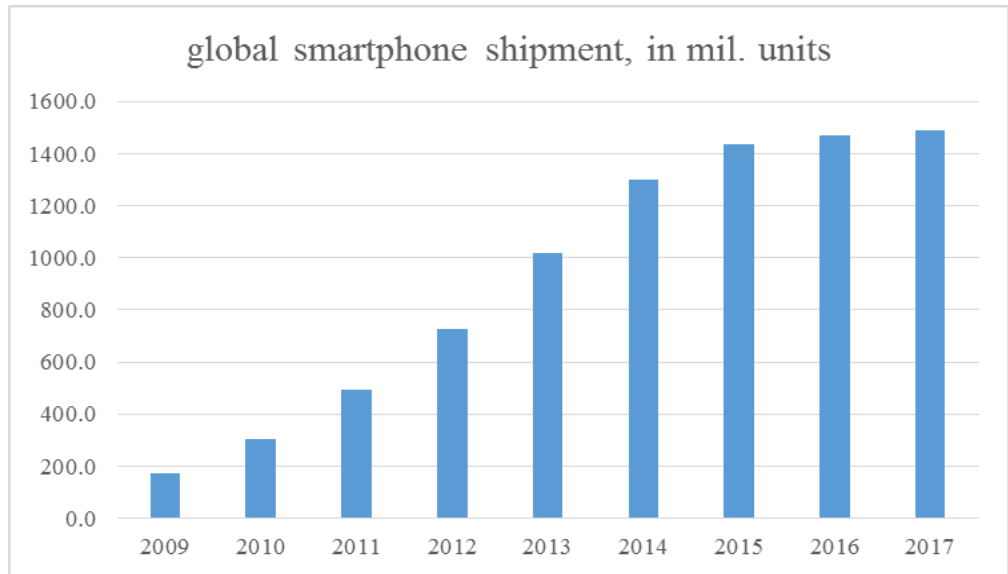

Figure 1: Global smartphone shipment, 2009-2017, in mil of units.

Source: Statista, 2017. https://www.statista.com/statistics/263441/global-smartphone-shipments-forecast/ 
During the past years, adults have spent more time on their smartphones than on the personal computers, and this trend will continue. Figure 2 illustrates the changes.

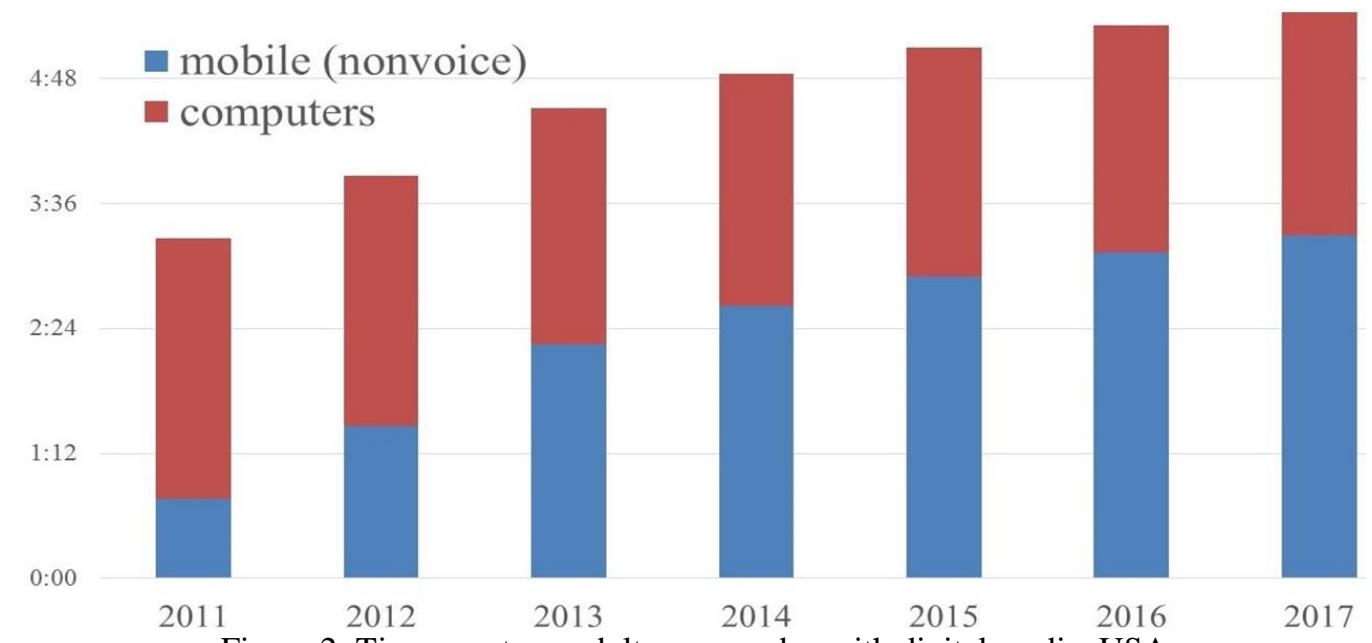

Figure 2: Time spent per adult user per day with digital media, USA

Source: http://www.smartinsights.com/mobile-marketing/mobile-marketing-analytics/mobile-marketing-statistics/

Fulgoni and Lipsman (2016) studied future mobile commerce. They discovered that marketers who looked only at the bottom-line effects of mobile shopper activities on retailing were missing important clues about the future. "Mobile still is not a significant channel in driving actual purchases," observe comScore, Inc. CEO, Gian M. Fulgoni, and VP of Marketing and Insights, Andrew Lipsman. Yet, "data from Deloitte forecast that in 2016, mobile will have influenced $\$ 689$ billion in U.S. in-store sales, up from just $\$ 158$ billion in 2012 - a compound annual growth rate of 45 percent. These mobile-influenced sales figures account for in-store product purchases for which a mobile device aided in the shopping experience".

According to a survey conducted by Clutch, a B2B research firm, almost seven in 10 mcommerce app users in the US access the apps to receive deals and offers. Nearly as many said they appreciate them for the flexibility to buy at any time. New data from The Integer Group illustrates the rapid shift of consumer behavior over the past few years. In surveys conducted in 2012 and 2016, the percentage of internet users who make purchases via mobile device rose substantially, from just a quarter in 2012 to nearly two-thirds last year (eMarketer, 2017).

Yang and Lee (2017) focused on distinguishing mobile interactivity (m-interactivity) from interactivity via fixed broadband Internet (e-interactivity). They explored several comprehensive dimensions of interactivity, and identify four key dimensions of m-interactivity by conducting both exploratory factor analysis and confirmatory factor analysis. They established the influence of m-interactivity on the consumer response variables of enjoyment, satisfaction, and loyalty, as well as the relationships among them.

Stewart and Cunningham (2017), and Ford (2017) studied the mobile form of marketing and revealed that this platform offered consumers unique experiences and a diverse selection of content. They discovered that with so many platforms at consumers' disposal, advertisers struggle to track the usage of each platform and the response to advertising on it. Marketers aim to reach, resonate with, and evoke a reaction from the right audience at the right time, which increases the importance of multiplatform metrics. They offered further theoretical explanations and managerial implications.

Hsu and Yeh (2018) find four critical success factors that influence M-commerce adoption: perceived ease of use, perceived usefulness, value-added and service functionality. In addition, these factors were identified as the cause and effect factors. The results of this study are presented to M-commerce service providers' in facilitating the development of wireless services. Lin, et al (2017) explored the determinants of consumers' use of mobile commerce, and their act of payment. They found that security concerns and privacy concerns are the most important factors.

Raphaeli, et al (2017) analyzed online consumer behavior in mobile and PC devices. They investigated and compared online consumer behavior on an e-retailer website in mobile versus PC devices, through the application of a web usage mining approach on clickstream data recorded in server-side log files. Online consumer behavior is characterized through both engagement measures and the discovery of common sequences of navigation patterns, using an innovative approach that combines footstep graph visualization with sequential association rule mining. They found that sessions conducted through mobile devices are more likely to consist of task-oriented behavior whereas sessions 
conducted through PC devices are characterized by a more exploration-oriented browsing behavior. They also found that certain sequence rules were associated with an increased likelihood of purchase in both mobile and PC sessions.

Chao (2017) investigated mobile commerce, which has emerged as an important sector in retail businesses, as US smartphones have penetrated near $80 \%$ of the population in 2017 . The average adult daily usage of smart phone outpaced personal computers for the first time, and the users do more commerce on their smartphones than on their personal computers. As predicted by eMarketer US mcommerce will be a half of the total ecommerce by 2020. As a result, marketers have spent advertisement on smartphones. The marketers realize that they can better target smartphone users through programmatic advertising, particularly when they find the phone users are interested in particular products they browse. This research, through an empirical survey, focuses on the effectiveness of mobile marketing. The research results confirm this marketing trend, and provide some useful insights for marketers in their future marketing endeavors.

The review of literature tenders a wide range of aspects for mobile commerce. While this study intends to focus only on the fundamental issues: the limited aspects of smartphone user behavior, and comparisons of computer and smartphone usages. The objective of the study intends to provide some insights to marketers that would help them better reach their customers.

\section{METHODOLOGY}

As this study intended to focus only on the fundamental issues: the limited aspects of smartphone user behavior, and comparisons of computer and smartphone usages.

\subsection{Variable Selection}

The variables that were selected are based on the literature review. Twelve research variables were identified and presented below. The respondents were asked to give their own experience on mobile phone uses, and also compare with the computer uses.

The following user behavior variables were evaluated:

1. How important to use smartphone for talking?

2. How important to use smartphone for obtaining news and sports?

3. How important to use smartphone for watching movies and videos?

4. How important to use smartphone for class work?

5. How important to use smartphone for playing games?

6. How important to use smartphone for online shopping?

7. How convenience and easiness to use smartphone?

8. How frequently do you use smartphone for comparative shopping?

\subsection{Sampling, Hypotheses, and Tests of Hypotheses}

The targeted sample respondents were college students in a large university in the northeast of the U.S. One-page survey questionnaires were distributed online over past semesters to target respondents, specifically with the aim of obtaining the opinions of the respondents who are often exposed to both traditional and digital advertising. The null hypotheses for this study stated:

$H_{1} \quad$ There is no significant difference in using smartphone for talking vs other means for talking, i.e. traditional landline phones.

$\mathrm{H}_{2} \quad$ There is no significant difference in using smartphone for finding news and sports info vs other means for gathering info.

$\mathrm{H}_{3} \quad$ There is no significant difference in using smartphone for watching movies and videos vs watching movies on television or go to movie theaters.

$\mathrm{H}_{4} \quad$ There is no significant difference in using smartphone for class work vs on computers or in classrooms.

$\mathrm{H}_{5} \quad$ There is no significant difference in using smartphone for playing games vs on game gadgets or televisions.

$H_{6} \quad$ There is no significant difference in using smartphone for comparative shopping.

$\mathrm{H}_{7} \quad$ There is no significant difference in using smartphone for online purchases?

$H_{8} \quad$ There is no significant difference in frequently using smartphone vs computer for comparative shopping. 
The alternative hypotheses state: there is significant relationship between the respondents' views of mobile media advertising and computer/laptop advertising over these selected variables.

One sample Student's $t$-test is used to test the hypotheses. A $t$-test is any statistical hypothesis test in which the test statistic follows a Student's $t$ distribution if the null hypothesis is supported. It is most commonly applied when the test statistic would follow a normal distribution if the value of a scaling term in the test statistic is known. The one sample Student's $t$-test requires that the dependent variable follow a normal distribution. When the number of subjects in the experimental group is 30 or more, the central limit theorem shows a normal distribution can be assumed. If the number of subjects is less than 30, the researcher should plot the results and examine whether they appear to follow a normal distribution. If the distribution appears to be non-normal, and/or if the number of test cases is significantly less than 30 , then a one sample median test, which does not require a normal distribution, should be used to test the hypothesis (Conover, 1980; Davis and Cosenza, 1985; Hamburg, 1977; SPSS ${ }^{\mathrm{X}}$, 2002; Wikipedia, 2012). Five percent of the $t$-Tests one tailed probability level was selected to signify the differences between preferences. When the scaling term is unknown and is replaced by an estimate based on the data, the test statistic (under certain conditions) follows a Student's $t$ distribution. The estimate value for testing hypotheses in this study is 3 , which is neutral.

\section{RESULTS AND DISCUSSIONS}

Five hundred questionnaires were prepared and distributed college students in a large university in the northeast of the U.S., of which three hundred ninety three were returned and usable. This represents roughly 78.6 percent response rate. The following table presents the background information of these respondents, including gender and income.

Table 1. Background Information of the Respondents

\begin{tabular}{|c|c|c|}
\hline \multirow[b]{4}{*}{ Age } & $<18$ & 1.5 \\
\hline & $19-35$ & 93.6 \\
\hline & $36-50$ & 4.6 \\
\hline & $>50$ & 0.3 \\
\hline \multirow[b]{2}{*}{ Gender } & male & 53.2 \\
\hline & female & 46.8 \\
\hline \multirow{4}{*}{$\begin{array}{l}\text { Family } \\
\text { income in } \\
\text { USD }\end{array}$} & $<35 \mathrm{k}$ & 15.0 \\
\hline & $35-50 \mathrm{k}$ & 21.6 \\
\hline & $50-75 k$ & 21.4 \\
\hline & $>75 \mathrm{k}$ & 42.0 \\
\hline \multirow[b]{2}{*}{ Education } & college & 91.1 \\
\hline & graduate & 8.9 \\
\hline \multirow{2}{*}{$\begin{array}{l}\text { Marital } \\
\text { Status }\end{array}$} & married & 7.6 \\
\hline & single & 92.4 \\
\hline \multirow{2}{*}{$\begin{array}{l}\text { Have a } \\
\text { smartphone }\end{array}$} & yes & 94.7 \\
\hline & no & 5.3 \\
\hline \multirow{3}{*}{$\begin{array}{l}\text { Phone's } \\
\text { Operating } \\
\text { system }\end{array}$} & Apple & 86.8 \\
\hline & Android & 13.0 \\
\hline & Windows & 0.3 \\
\hline
\end{tabular}

Overall, the means of computer internet advertising are higher than those of smartphone advertising. Table 2 shows the Marginal Homogeneity Test results. It indicates that only one of paired variables test result shows significance levels less than 5\% (highlighted in bold). Therefore, one hypothesis where there is significant differences between the respondents' views of smartphone advertising versus computer internet advertising messages is rejected. The other 11 paired variables test results show significance levels more than 5\%. Therefore, these hypotheses are accepted: for these promotional elements there are no significant differences in the respondents' awareness based on smartphone advertising messages and the computer internet advertising messages. 
Table 2: One-Sample t-Test Results, test value $=3$, neutral, degree of freedom $=392$

\begin{tabular}{|l|c|c|c|}
\hline Variables & $\begin{array}{c}\text { Mean } \\
\text { Diff }\end{array}$ & $\boldsymbol{t}$ & $\begin{array}{c}\text { Sig. (2- } \\
\text { tailed) }\end{array}$ \\
\hline 1. How important to use smartphone for talking? & $\mathbf{- 0 . 5 2 4}$ & $\mathbf{- 7 . 4 6 3}$ & $\mathbf{0 . 0 0 0}$ \\
\hline 2. How important to use smartphone for news and sports? & $\mathbf{- 0 . 6 5 1}$ & $\mathbf{- 9 . 9 8 8}$ & $\mathbf{0 . 0 0 0}$ \\
\hline 3. How important to use smartphone for watching movies and videos? & $\mathbf{- 0 . 8 0 4}$ & $\mathbf{- 1 2 . 5 3 5}$ & $\mathbf{0 . 0 0 0}$ \\
\hline 4. How important to use smartphone for class work? & $\mathbf{- 1 . 1 1 2}$ & $\mathbf{- 1 8 . 0 4 4}$ & $\mathbf{0 . 0 0 0}$ \\
\hline 5. How important to use smartphone for playing games? & $\mathbf{- 1 . 1 2 7}$ & $\mathbf{- 1 8 . 6 0 3}$ & $\mathbf{0 . 0 0 0}$ \\
\hline 6. How important to use smartphone for online shopping? & $\mathbf{- 0 . 2 4 2}$ & $\mathbf{- 3 . 9 0 6}$ & $\mathbf{0 . 0 0 0}$ \\
\hline 7. How important to use smartphone for online purchases? & $\mathbf{- 0 . 7 2 0}$ & $\mathbf{- 1 3 . 2 4 7}$ & $\mathbf{0 . 0 0 0}$ \\
\hline 8. How frequently do you use smartphone for online purchases? & -0.173 & -0.929 & 0.353 \\
\hline
\end{tabular}

\subsection{Managerial implications and recommendations}

The mean differences as compared to the test value of 3 which is neutral tell the researchers how relatively important of these variables. The results show that seven variables have significant levels less than 5\%, and these corresponding hypotheses are rejected. These variables are How important to use smartphone for talking? How important to use smartphone for news and sports? How important to use smartphone for watching movies and videos? How important to use smartphone for class work? How important to use smartphone for playing games? How important to use smartphone for online shopping? How important to use smartphone for online purchases? The rejections of these hypotheses indicate the significant differences exist in using smartphone as compared to other means.

One variable, test result shows significant level of $35.5 \%$ in How frequently do you use smartphone for online purchases, therefore this hypothesis is accepted, as there is no difference.

\subsection{Limitations and future research}

The academic research that focuses on comparisons between computer internet and smartphone user behavior is limited, and the application and use of smartphone is evolving, as the time that smartphone users is picking up as compared to computers and other means, i.e. TV, radio, and printed media. It may take some years before significant research publications are available. As a preliminary and exploratory research, this study has provided if only limited glimpses of some fundamental aspects of smartphone usages.

Further in-depth research should delve more into the factors and elements that predict the effectiveness and efficiency of computers versus smartphone. Would consumers eventually prefer more smartphone shopping in the future? Does the younger generation differ from the older generation since younger people spend more time on their smartphones? As some of the respondents commented, they find using the smartphone enable them to handily obtain products and/or service related information. These issues should also be addressed in future research.

\section{ABOUT AUTHORS}

Chiang-nan Chao, PhD, Professor of Management, earned his MBA from Lamar University, and his Ph.D. in Supply Chain Management and International Business from Arizona State University. His articles, books, book chapters, conference papers, conference presentations, and case studies, etc. have published in many leading journals and conferences, i.e., Journal of World Business, the Journal of Supply Chain Management, the International Journal of Physical Distribution and Logistics Management, the Journal of Strategic Marketing, the Journal of Education for Business, the Industrial Marketing Management, Organizations and People, Journal of Teaching in International Business, etc.

\section{REFERENCES}

[1] Chao, C. (2017). Emergence Impacts of Mobile Commerce: An Exploratory Study, Journal of Management and Strategy, Volume 8, No. 2, pp. 63-70.

[2] Cisco, (2017). Virtual Network Index Report. Retrieve http://www.cisco.com/c/en/us/solutions/collateral/service-provider/visual-networking-index-vni/mobile-whitepaper-c11-520862.html

[3] Conover, W. J. (1980). Practical Nonparametric Statistics, 2nd ed., New York: John Wiley \& Sons, pp. 213-337 \& 344-384. 
[4] Davis, D., \& Cosenza R. M. (1985). Business Research for Decision Making. Boston: Kent Publishing.

[5] eMarketer, (2017), Source: Source: http://www.emarketer.com/Article/Mobile-Account-More-than-Half-of-DigitalAd-Spending-2015/1012930

[6] Ford, J. B. (2017). What Do We Know about Mobile Media and Marketing? Journal of Advertising Research, Vol. 57, Iss. 3. 1 September 2017. DOI: 10.2501/JAR-2017-032.

[7] Fulgoni, G. M., \& Lipsman, A. (2016). The Future of Retail is Mobile, Journal of Advertising Research, Dec 2016 , 56 (4) 346-351; DOI: 10.2501/JAR-2016-041

[8] Hamburg, M. (1977). Statistical Analysis for Decision Making. San Diego: Harcourt.

[9] Hsu, C. W., \& Yeh, C. C. (2018). Understanding the critical factors for successful M-commerce adoption, International Journal of Mobile Communications, 2018 Vol.16, No.1, pp.50 - 62

[10] https://en.wikipedia.org/wiki/List_of_countries by 4G_LTE_penetration

[11] http://www.smartinsights.com/mobile-marketing/mobile-marketing-analytics/mobile-marketing-statistics/

[12] Lin, W. R., Wang, Y. H. \& Shih, K. H. (2017). Understanding consumer adoption of mobile commerce and payment behavior: an empirical analysis. International Journal of Mobile Communications, Vol.15, No.6, pp.628 654. DOI: 10.1504/IJMC.2017.10005646

[13] Raphaeli, O., Goldstein, A., and Fink, L. (2017). Analyzing online consumer behavior in mobile and PC devices: A novel web usage mining approach, Electronic Commerce Research and Applications, Vol. 26, November-

December, pp. 1-12. https://doi.org/10.1016/j.elerap.2017.09.003

[14] SPSS $^{\mathrm{X}}$, Advanced Statistics, 7.5. Chicago, IL: SPSS Inc. 2002.

[15] Statista, 2017. https://www.statista.com/statistics/263441/global-smartphone-shipments-forecast/

[16] Stewart, K \& Cunningham, I. (2017). Examining Consumers' Multiplatform Usage And Its Contribution to Their Trust in Advertising--The Impact of the Device on Platform-Use Frequency And Trust in Advertising across Platforms, Journal of Advertising Research, Vol. 57, Iss. 3, 1 September 2017. DOI: 10.2501/JAR-2017-003.

[17] Wikipedia, $2012 \quad$ http://en.wikipedia.org/wiki/Student's_t $t$-test; $\quad$ Source: $\quad \underline{\text { http://www- }}$ users.cs.umn.edu/ ludford/Stat_Guide/1_Sample_t.htm

[18] Yang, S. \& Lee, Y. J. (2017). The Dimensions of M-Interactivity and Their Impacts in the Mobile Commerce Contex, International Journal of Electronic Commerce, Volume 21, Number 4, pp. 548-571. 